\title{
Educar para la convivencia, Educar para la paz
}

Keywords: derecho; legislación; jurisprudencia; animal

El respeto por los animales es una actitud que se educa. Despertar la sensibilidad por los animales, por su bienestar, por el respeto de sus intereses, puede y debe fomentarse en todos los niveles de la población. El lenguaje y los medios que se empleen pueden diferir, pero lo que no puede diferir es la convicción de que con ello estamos contribuyendo a mejorar la convivencia entre los humanos y los animales y entre los humanos mismos, pues, en definitiva, una cultura de la convivencia es una cultura de la paz.

No hace mucho, alguien me comentó: "Mira, los que hemos crecido cazando pájaros con trampas, arrancando alas a las moscas por simple diversión, o haciendo disección de un ratón blanco en el colegio, le damos a todo lo que se mueve. No somos recuperables...”. Me quedé pensativa y sonriendo, por la forma tan gráfica de expresar su rechazo, a ver en los animales algo más de lo que había recibido de su entorno, algo útil, que está de forma ilimitada a nuestra disposición. Era una expresión cruda de que, lo que ves a tu alrededor, la falta de correctivos o de rechazo ante el maltrato animal por parte de la sociedad que te rodea, genera indiferencia ante cualquier tipo de maltrato animal y consiente hablar de esas acciones, sin mayor empacho, como de “travesuras de niños”. Cuando, en realidad, no es así. Nada es indiferente en la formación de una persona, no sólo en la infancia. Todo nos influye, positiva y negativamente. Sólo que, ciertamente, estoy de acuerdo con mi interlocutor, en que, cuanto antes se empiece a educar en la sensibilidad hacia los animales, tanto mejor. En otros términos, también un adulto se puede "recuperar" hacia actitudes de respeto, de sensibilidad, de admiración y consideración por los animales, pero en los estadios en que el ser humano está abriéndose al mundo que le rodea, tanto en la infancia, la adolescencia y la juventud, es más necesario. También se está más receptivo y, por ello, puede resultar más importante.

Estoy proponiendo que en la Educación Primaria y Secundaria, se incluyan Programas educativos para fomentar actitudes de conocimiento y respeto por los animales, de sus intereses, necesidades y derechos. Está muy bien que se diga a los niños (y a los adultos) que un animal no es un juguete, no es una cosa que se usa y se tira, pero, quizá, hay que ir más allá.

Se trata de esforzarse en crear Programas Educativos, sometidos a los controles que se requiera, aptos para ser impartidos en todos los niveles de la enseñanza Primaria y Secundaria. Hay en este momento, iniciativas de carácter privado, muy dignas de ser tenidas en cuenta, que están supliendo la falta de tales Programas integrados en la Enseñanza oficial y privada. Me refiero, a título de ejemplo, a los Programas de charlas educativas en el respeto animal de los Voluntarios de la Protectora de Sabadell y a los Programas de charlas y actividades que se desarrollan en la Comunidad Valenciana desde hace unos años , con la misma finalidad. En la Universitat Autònoma de Barcelona, con carácter pionero, vengo impartiendo la asignatura de Derecho Animal desde hace cuatro años y, en enero de 2011, empezamos un Postgrado de especialización en Derecho Animal (“Animales, Derecho y Sociedad”), que es el primero que se imparte en una Universidad española, de estas características.

Se trata de inculcar que la violencia ejercida contra un animal es rechazable, como cualquier tipo de violencia ejercida contra alguien más débil, e incluyo aquí a los propios niños, a las mujeres, a los ancianos, a los que son diferentes. Necesariamente, un tipo de formación con estas premisas, genera actitudes de respeto globales. 
Hace tiempo que leí que las palabras más repetidas en inglés son please y sorry. En efecto, ir en metro o autobús a hora punta, es un billete seguro a los empujones, pero pocas veces, ante las necesarias apreturas se oye a alguien decir: disculpe, o lo siento. Es un ejemplo nimio, de cómo hemos ido derivando hacia una sociedad malhumorada y poco respetuosa con el otro.

Es una tarea, la de educar para la convivencia y para la paz, que ha recorrido hasta ahora senderos muy necesarios y a la vista están los resultados en forma de reciente protección a colectivos discriminados por débiles, por cosificados (mujeres, ancianos, inmigrantes, gays). No podemos eludir, en modo alguno, la educación para la convivencia y para la paz, a través de la educación en el respeto por los animales.

LA EDITORA

Teresa Giménez-Candela Catedrática de Derecho Romano Animal Law Profesor Universitat Autònoma de Barcelona 